\title{
Measles and Rubella Serosusceptibity among Population Vaccinated with Different Schedule of Vaccination: the potential impact on measles elimination in Iran.
}

\section{Hana Saffar}

Department of antimicrobial and clinical Pathology, IKHC, Teheran University of Medical Sciences, Tehran Iran.

\section{Maryam Khalifeloo}

The University of Manchester Faculty of Biology Medicine and Health mohammed-Jafar Saffar ( $\sim$ saffar@softhome.net )

Mazandaran University of Medical Sciences https://orcid.org/0000-0002-9335-6262

\section{Ali-Reza Abdollahi}

Department of antimicrobial and clinical Pathology, IKHC, Teheran University of Medical Sciences, Tehran Iran.

\section{Mohammad-Reza Parsaei}

Deputy of Health, Mazandaran University of Medical Sciences.

\section{Gholam-Reza Ghorbani}

Deputy of Health, Mazandaran University of Medical Sciences.

\section{Samaneh Salarvand}

Department of antimicrobial and clinical Pathology, IKHC, Teheran University of Medical Sciences.

\section{Mohsen Aarabi}

Deputy of Health, Mazandaran University of Medical Sciences.

\section{Research article}

Keywords: Measles, Rubella, MMR, Measles elimination, congenial rubella syndrome, Iran

Posted Date: October 23rd, 2020

DOl: https://doi.org/10.21203/rs.3.rs-40094/v2

License: (9) This work is licensed under a Creative Commons Attribution 4.0 International License. Read Full License 
Version of Record: A version of this preprint was published on March 25th, 2021. See the published version at https://doi.org/10.1186/s12879-021-05970-7. 


\section{Abstract}

Background: In addition to scheduled 2-doses monovalent measles vaccine (mMV) immunization of Iranian children since 1984, a nationwide campaign of measles-rubella (MR) immunization among 5- 25 years-old population in December 2003 was conducted. From 2004 mMV was replaced with measlesmumps-rubella (MMR) vaccine. Despite a high vaccination coverage, outbreaks of measles occurred in the country. Study was designed to investigate seroimmunity status against measles and rubella among various age groups of population who were vaccinated with different schedule since 1984. Also, immunologic response to revaccination in seronegative subjects was evaluated.

Methods: From 1 November 2017 to 30 June 2018 a cross- sectional study among 7- 33 year old (born 1984-2011) healthy population with documented history of measles vaccination was conducted. Based on their age and history of vaccination status categorized as GA: 20-2333 years old; vaccinated with 1-2 dose of $\mathrm{mMV}$, and also MR revaccinated. GB: 15-19 years, vaccinated only with 2-doses of $\mathrm{mMV}$ at the ages of 9 and 15 months and MMR 2-5 years later. GC: 12-14 years and GD: 7-11 years; vaccinated with 2- dose of MMR vaccine at the ages 15 months - 6 years, and 12-18 months respectively. Collected sera were assessed to measure antimeasles and antirubella IgG antibodies concentration. Four to 6 weeks after revaccination of seronegative subjects, antimeasles-antirubella IgM and IgG antibodies were rechecked. Collected data were analyzed using descriptive statistical methods.

Results: Totally 635 individuals, 312 female were included. Relative distribution of subjects in each group was as: GA: $98, \mathrm{~GB}: 295, \mathrm{GC}: 139$, and GD: 103 persons. Overall, $12.28 \%$ and $18.4 \%$ of population were soronegative, and varied greatly between groups: $2 \%-0 / 0 \%, 15.2 \%-25.0 \%, 11.5 \%-17.2 \%$; and $14.6 \%-18.4 \%$, to measles and rubella, respectively. After revaccination, $92 \%$ and $94.9 \%$ showed $1 \mathrm{gG}$ response to measles and rubella vaccine respectively.

Conclusion: Despite high coverage rate with measles and rubella containing vaccine, a significant numbers of vaccinated subjects lost their seroprotection were seronegative, possibly because of secondary vaccine failure. This may affect measles-rubella elimination goal in the country. If these data were confirmed by further studies, more strengthen regional/ national supplementary immunization activity should be considered.

\section{Background}

Measles, a highly contagious viral disease, is a major public health concern worldwide. which affect susceptible subjects of all ages, and remains one of the leading caused death, especially in young children. A safe and effective vaccines are available for more than 50 years ${ }^{(1)}$. Global measles vaccination is estimated to have prevented more than 23.2 million deaths during 2000-2018. However In 2018, there were more than 140/000 measles death globally, mostly among children under the age of 5 years $^{(2)}$. Measles is more severe and with a higher mortality rate in infants less than 12 months of age ${ }^{(1,3)}$. Age at vaccination is one of the key host- related determinant of vaccine efficacy. The optimal 
age for measles immunization must be balanced with the age at which the largest percentage of vaccinees respond to measles vaccine (MV) and the relative risk of acquiring measles infection ${ }^{(3-5)}$. The World Health Organization (WHO) recommendation for measles vaccination in developing countries was administering 2 dose MV at the age 9 and 15 month $^{(1)}$. However, results of studies revealed that measles vaccination at the age less than 12 month is associated to reduced immune response rate because of maternal antibodies interference and immature immune system ${ }^{(3-5)}$. To interrupt measles virus transmission in a community, a population immunity of rate $>93-95 \%$ with $>95 \%$ 2-doses vaccine coverage in all districts of the country is required ${ }^{(1-6)}$. For measles, this rates of immunity demand that > $95 \%$ of population must be successfully vaccinated with 2 - doses of measles virus containing vaccines after 12 months of age. This program will result to seroprotection rates of $95-98 \%$ in vaccine recipients ${ }^{(1,3,9)}$. Following universal measles immunization, the number of measles cases reduced markedly in the world, and even eliminated in some countries. However, During recent years, the numbers of measles cases and outbreaks has started to increase even in those countries declared elimination and some cases occurred among fully vaccinated individuals ${ }^{(7-16)}$. From January- to July $31,2019,182$ countries reported 364,808 measles cases to the WHO. This surpass the 129. 239 reported during the same period in $2018^{(7)}$.

Rubella is a mild viral infection that affect unvaccinated children and adults. If a nonimmune women gets rubella while pregnant, especially in her first trimester, serious consequences including miscarriage, fetal death, stillbirth and having infants born with congenital rubella syndrome (CRS) may occur. CRS is a group of devastating birth defects that include blindness, deafness, cardiac defect and mental retardation that make it a public health priority. CRS is a vaccine- preventable congenital anomalies ${ }^{(17)}$. A safe and highly efficacious vaccine is available. WHO recommended that all countries introduce rubella vaccine in their national routine or supplementary Immunization program from 2000. Following vaccination, the number of reported rubella cases declined from 610894 in 2000 to 14621 in $2018^{(18)}$.

In Iran, during the prevaccine era, measles and rubella were endemic and nearly $150,000-500,000$ cases of measles with death rate of $10-15 \%$ a high mortality rate were reported yearly ${ }^{(19)}$. Also, more than threefourth of adolescents and childbearing age women acquired anti-rubella immunity by natural infection ${ }^{(20-}$ 22) and the incidence of CRS was estimated to be $2 / 10,000$ live birth ${ }^{(23)}$. After establishment of WHO Expanded Programme of Immunization (EPI) in Iran in 1984, vaccination coverage rates for the first and second dose of MV given at the ages of 9 and 15 months increased to $>90 \%$ by the mid-1990's, and the numbers of measles cases decreased to 2652 in year 1996. In response to increased number of measles cases particularly among older age groups, and to prevent CRS a nationwide measles- rubella (MR) immunization campaign targeting persons 5- 25 year old in December 2003 was conducted ${ }^{(19)}$.

After mass MR immunization program, many seroprevalence studies among MR vaccinated subjects were conducted. Results revealed that nearly $87 \%$ to $63.2 \%-92 \%$ and $87-99 \%$ of vaccinees got seroprotection against measles and rubella ${ }^{(24-29)}$ Table 1. 
Table 1. Measles cases / outbreaks reported in Iran Since 2006 to 2016.

\begin{tabular}{|c|c|c|c|c|}
\hline Author/province & $\begin{array}{l}\text { Years of } \\
\text { study }\end{array}$ & No of cases & Age groups & vaccinated status \\
\hline \multirow{2}{*}{$\begin{array}{l}\text { Nyati J, et al/ } \\
\text { Sisdtan- } \\
\text { Bluchestan }^{12}\end{array}$} & $2006-11$ & \multirow{2}{*}{$\begin{array}{l}456 \text { cases } 56 \% \\
\text { serology } 19 \% \text { clinical } \\
85.8 \% \text { Iranian } \\
F=\text { Male }\end{array}$} & Less than one & \multirow{2}{*}{$\begin{array}{l}\text { Among confirmed one } \\
\text { dose: } 23 / 1205: 11.2 \% 2- \\
\text { dose: } 57 / 205: 27.8 \% \text {, } \\
\text { not vaccinated : } 113 / 205 \\
55.1 \%\end{array}$} \\
\hline & Focal & & $\begin{array}{l}\text { Serologic } \\
\text { confirmed <1 } \\
\text { yr=7-8\&, 1-4 yr: } \\
39.0 \% 5-9 \text { yr: } \\
34.1 \%, 10- \\
14+0.7 \%\end{array}$ & \\
\hline \multirow{2}{*}{$\begin{array}{l}\text { Izadi s } \\
\text { southeast of } \\
\text { Iran }{ }^{13}\end{array}$} & $2009-10$ & \multirow{2}{*}{$\begin{array}{l}126 \text { cases } 2 \text { main } \\
\text { outbreaks }\end{array}$} & \multirow{2}{*}{$\begin{array}{l}\text { All age groups } \\
42 \% \geq 7 \mathrm{yrs} \\
6.3 \%>20 \mathrm{yrs}\end{array}$} & \multirow{2}{*}{$\begin{array}{l}\text { 2-dose vaccine efficacy } \\
=74.2 \%\end{array}$} \\
\hline & Focal & & & \\
\hline Moghaddam $^{14}$ & 2012 & 7 cases & $1^{\text {st }}$ Afghan 16 & 4 vaccinated 3 with $2-$ \\
\hline Fars province & focal & & $\begin{array}{l}12 \mathrm{~m}, 34 \mathrm{~m}, 94 \\
35 \mathrm{yr}\end{array}$ & unknoun \\
\hline \multirow{3}{*}{$\begin{array}{l}\text { Karami M } \\
2017 \\
\text { National }\end{array}$} & \multirow[t]{3}{*}{$\begin{array}{l}20 / 29 \\
2014 \\
\text { national }\end{array}$} & \multirow[t]{3}{*}{$\begin{array}{l}\text { 232: } 2012 \text { and } \\
142: 2014\end{array}$} & \multirow[t]{3}{*}{$\begin{array}{l}\text { Less than three- } \\
\text { fourth yrs to } \\
>25 y e a r s\end{array}$} & $\begin{array}{l}22.7 \% \text { under the age of } \\
\text { vaccination }\end{array}$ \\
\hline & & & & $36.5 \%$ unvaccinated \\
\hline & & & & $19.3 \%$ vaccinated \\
\hline \multirow{4}{*}{$\begin{array}{l}\text { Piri N }{ }^{16} 2019 \\
\text { National }\end{array}$} & \multirow{4}{*}{$\begin{array}{l}2014- \\
2016 \\
\text { review } \\
\text { national }\end{array}$} & \multirow{4}{*}{$\begin{array}{l}759 \text { cases } \\
\text { particularly } 53 \\
\text { outbreaks } 86 \% \text { only } \\
\text { one cases } \\
\text { particularly } 9 \% \\
\text { unknoun source }\end{array}$} & $<1$ yr $31.1 \%$ & $\begin{array}{l}1-14 \text { years: } 22.3 \% \\
\text { vaccinated }\end{array}$ \\
\hline & & & $1-4$ y $13.2 \%$ & \\
\hline & & & $5-911.6 \%$ & unvaccinated $20.4 \%$ \\
\hline & & & $10-14$ y $7.5 \%$ & vaccination \\
\hline
\end{tabular}

Since March 2004, in continuing to protect against rubella and provide protection against mumps infection, MV was replaced by 2- dose of measles-mumps-rubella (MMR) vaccine, scheduled initially at the ages of $>12$ months and 4- 6 years, and after 3 years then changed to 12 and 18 months of age. This schedule is ongoing with more than $95 \%$ coverage rates in all districts of the country ${ }^{(19)}$. These changing program led to accumulation of a birth cohort that were born between November 1998 to March 2004 that were vaccinated only with 2- doses of MV at the age of 9 and 15 months. However, to provide protection against mumps and rubella, this birth cohert with one dose of MMR vaccine at time of school entrance ( 2 to 5 year after last dose of $\mathrm{MV}$ ) were revaccinated. 
In 2019, WHO, Eastern Mediterranean Region Verification Committee declared elimination of measles and rubella in Iran ${ }^{(30)}$. However, during recent years, small outbreaks of measles from some parts of the country were reported Table 1 . The origin of measles virus causing these outbreaks were originated from neighbor countries Piri, Salimi ${ }^{(16,31)}$.

To prevent reestablishment of indigenous or imported measles virus transmission in the Iran, a high levels of seroprotection against measles in the population must be sustained. The results of studies from some parts of the country years after MR campaign on the Immunogenicity of MMR vaccine given after 12 month of age indicated suboptimal seroconversion rate Table $2^{(32-37)}$. However, little Information about the levels of measles and rubella protection among children, adolescents and adults vaccinated with different schedules are available. This study was designed to investigate the prevalence rates of measles and rubella immunity among different various age groups that were vaccinated with different program, and also determine the relative roles of secondary vaccine failure (SVF) as a possible causes of susceptibility in East of Mazandaran province- North of Iran.

\section{Methods And Participants}

Descriptive-analytical cross-sectional study from 1 November 2017 to 30 June 2018 in the East of Mazandaran province, North of Iran was conducted. Study subjects among healthy children, adolescents and adults born during years 1984- to 2011 with documented history of measles vaccine Immunization based on their medical booklet or the primary health care centers records were simple randomly selected. The region consist of three main districts with nearly 460000 population. In each district based on its population density some primary health care centers $(\mathrm{PHC})$ was established. All the basic health requirement including prenatal care vaccination of children of affiliated families are met in these centers. Also all health related events are recorded in each famity file in the PHC. For this study purpose, the families file affiliated to each PHC were reviewed. healthy subjects born within 1984-2011 were recrvited. Based on the numbers of eligible individuals, study subjects among healthy children, adolescents and adults with documented history of vaccination by simple random sampling method were selected. For this study, the majority of selected persons were students (primary and high school) that their vaccination status was rechecked by their booklet record copy in their school life. MR revaluation history of some adults was based on their recall. Individuals with acute diseases, history of recent febrile exanthematous illnesses, chronic or metabolic illnesses, malignancies, immunodeficiency or receipt of blood/ blood product within last one year, recipient of additional dose of measles containing vaccine after the recommended schedule except those who received MR vaccine during nationwide measles-rubella campaign Immunization receipient of MMR vaccine at school entrance among birth cohort 1998-2003, and pregnant women were excluded. According to their age and vaccination status, study subjects were categorized as following; Group A: subjects were born during year 1984 to October 1998, (age range: 2033 years) most of them were vaccinated with 1-2 doses of measles vaccine at the ages of 9 and 15 months and also were reimmunized with MR vaccine during national campaign of MR Immunization conducted among 5- 25 years old individual at Dec 2003 they were vaccinated with 3 dose of measles 
and one dose of rubella vaccine. Group B: Include persons born during November 1998 to March 2004 (age range 15-19 years); this birth cohort only with 2- doses of monovalent measles vaccine (mMV) at the age of 9 and 15 months were vaccinated. Also, they were reimmunized, with additional dose of MMR vaccine at time of school entrance (6years of age), therefore, they were immunized measles with 3 dose and rubella and mumps with one dose of vaccine. Group C: individuals who were 12 month- old at March 2004 (Age range: 11-14 years) and were vaccinated with

2- doses of MMR vaccine at the age of 12- 15 month and 4-6 year to March 2007, and the group D: who were vaccinated since April 2008- 2011 (Age range 7-10 years) with 2-dose of MMR at the age of 12 and 18 months. These are presented in Table 2 . The study protocol used the standard ethical guidelines and was approved by the Ethic committee of Mazandaran and Tehran Universities of Medical Science: IR.MAZUMS. Rec.1396.3074 and Tehran IR.TUMS.IKHC.Rec.1399.075, respectively.

After obtaining informed written consent from guardians/ individuals, $5 \mathrm{ml}$ of venous blood of all enrolled subjects were collected. Sera was stored at $20^{\circ} \mathrm{C}$ to measure anti-measles and anti-rubella IgG antibodies qualitatively at the university laboratory by ELISA method using Vircell Microbiologic ELISA measles and rubella lgG/lgM kits (vircell, S. L. parquet Technologico dela salud. Avecina 8. 18016 Granada. Spain), based on manufacturers instructions. Measles and rubella IgG antibody titers $>11 \mathrm{IU}$ were considered positive and titer less than 9 as negative. Titers 9-11 IU $/ \mathrm{mL}$ was rechecked and if $>11$ considered positive. The sensitivity and specifity of kit for measles IgG were $99 \%$ and $92 \%$ and for IgM $100 \%$ and $98 \%$ respectively. These rates for rubella IgG were $96 \%$ and $97 \%$, and IgM: $97 \%$ and $100 \%$, respectively. Mean concentration of antibody (MCA) in each group for both viruses were calculated. The proportion of seropositive individual, totally and within each group were calculated. Seronegative persons with one dose of MMR vaccine were revaccinated. Four to 6 weeks after boosting, sera for measles specific lgM and IgG and rubella IgG were tested. Those subjects who, showed both IgM and IgG seroconvertion were considered as primary vaccine failure (PVF), and those, only IgG seroconverted as secondary vaccine failure (SVF). MCA of seroconverted seropositive individual calculated before and after boosting. Also, MCA of immune subjects that were boosted calculated and was compared with the level before. Collected data was analyzed using SPSS version 16.0. The descriptive statistical method was used in the form of percentile for seropositivity and response rate to revaccination.

The chi-square and student t-test were used to find differences between variables as appropriate. Results were considered to be statistically significant when the $P$ value was less them 0.05 .

\section{Results}

For this study, totally 635 individuals were participated. The their demographic characteristics and vaccination status are presented in Table 2.

Table 2: Demographic characteristics of studied population based on their age and vaccination status, and time elapsed since receipt the last dose of vaccine, east of Mazandaran, North of Iran. 


\begin{tabular}{|c|c|c|c|c|c|}
\hline $\begin{array}{l}\text { studied groups } \\
\text { variable }\end{array}$ & A & B & C & D & Total \\
\hline No of subjects & 98 & 295 & 139 & 103 & 635 \\
\hline \multirow[t]{2}{*}{ Age Range yr } & $20-33$ & $15-19$ & $11-14$ & $7-10$ & $7-33$ \\
\hline & $\begin{array}{l}1984- \\
1998\end{array}$ & $1999-2003$ & $2004-2007$ & 2007 & $\begin{array}{l}1984- \\
2018\end{array}$ \\
\hline Female/male ratio & $59 / 39$ & $139 / 156$ & $75 / 64$ & $49 / 54$ & $322 / 313$ \\
\hline $\begin{array}{l}\text { Time elapsed since the last } \\
\text { dose of vaccination }\end{array}$ & $\begin{array}{l}15 \mathrm{yr} / \\
2003\end{array}$ & $\begin{array}{l}13-15 \mathrm{yr} \\
/ 2004-07\end{array}$ & $\begin{array}{l}10-13 \mathrm{yr} \\
/ 2004-07\end{array}$ & $\begin{array}{l}7-10 \mathrm{yr} / \\
2008-11\end{array}$ & \\
\hline history of $\mathrm{MV}_{1}$ and $\mathrm{MV}_{2}{ }^{*}$ & + & + & - & & - \\
\hline History of MR & + & - & - & - & - \\
\hline History of $\mathrm{MMR}_{1}$ and $\mathrm{MMR}_{2}{ }^{* \star}$ & - & - & + & + & - \\
\hline
\end{tabular}

*: $\mathrm{MV}_{1,2}$ measles vaccine dose 1 and dose 2

**: $\mathrm{MMR}_{1,2}$ measles-mumps-rubella vaccine dose 1 and 2.

MV: measles vaccine, MMR: measles-mumps-rubella, yr: year, Mo: month, GB: this group, in addition to receipt 2 dose of MV at the age 9 and 15 months, with one dose of MMR vaccine at time of school entrance were immunized.

Of 635 studied subjects 78 (12.23\%) were serologically susceptible to measles and 117 (18.4\%) to rubella. The prevalence rates of measles and rubella susceptibility among different age groups were varied significantly and markedly and were presented in table 2. As are seen, the highest rates of susceptibility to both infection are seen in the group B with $15.3 \%$ and $25.0 \%$, followed by group $D$ with $14.6 \%$ and $18.4 \%$ to measles and rubella, respectively. The highest seroprotection rate $(98 \%$ and $100 \%)$ was observed among oldest subjects, who were MR revaccinated. Also, a significant differences between MCA related to group $A$ and other groups for measles and group $A$ with $D$ for rubella were detected. $P=0.000,0.006,0.001$

After revaccination of 171 persons susceptible to measles (78) and/or rubella (117), only 71 subjects (50 measles and 59 rubella susceptible) was agreed to give blood sample for further study. As are were shown in table $3,92 \%$ and $94.9 \%$ of revaccinated persons responded to MMR boosting and become IgG seroconverted against measles and rubella, respectively. None of the boosted subjects showed evidence of anti-measles anti-rubella IgM response, indicating possibly acquired serosuseptibility because loss of acquired immunity over time and SVF. MCA induce after revaccination among measles seroimmune 
subjects was not associated with immunity enhancement: MCA before 20.06 VS $18.35, P=0.08$, similar to this results was also observed for rubella; $22.63 \mathrm{VS} 21.45, \mathrm{P}=0.603$. The levels of MCA acquired after revaccination of seroimmune individuals to measles and rubella was not statistically significant with that levels were detected before for both agents: for measles $18.35 \mathrm{IU} / \mathrm{mL}$ VS $20.06 \mathrm{P}=0.149$, and for rubella; 22.63 VS 22.63, $P=0.603$.

Table 3. Measles and rubella immunity status among different age groups population vaccinated with various vaccination schedule and their response to revaccination, East of Mazandaran province, North of Iran.

\begin{tabular}{|c|c|c|c|c|c|}
\hline \multirow{2}{*}{$\begin{array}{l}\text { Groups(birth } \\
\text { date) }\end{array}$} & $\mathrm{GA} \mathrm{N}=98$ & GB N=295 & $\mathrm{GC}^{1} \mathrm{~N}=139$ & GD N=103 & Total N=635 \\
\hline & 1984-1998 & 1999-2003 & 2004-2007 & $2008-2011$ & $1984-2011$ \\
\hline $\begin{array}{l}\text { vaccination } \\
\text { status }\end{array}$ & $\begin{array}{l}2 \text { dose } \\
\text { mMV \& one } \\
\text { MR, 6-19 yr } \\
\text { later }\end{array}$ & $\begin{array}{l}2 \text { dose } \mathrm{mMV} \\
\& \text { one MMR, } \\
1-5 \text { yr later }\end{array}$ & $\begin{array}{l}2 \text { dose } \mathrm{mMV} \\
\text { at age } 12-15 \\
\text { mo and } 6 \mathrm{yr} \\
\text { later }\end{array}$ & $\begin{array}{l}2 \text { dose } \\
\mathrm{mMV} \text { at } \\
\text { age } 12 \text { and } \\
15 \mathrm{mo}\end{array}$ & $\begin{array}{l}\text { different } \\
\text { schedule }\end{array}$ \\
\hline \multicolumn{6}{|l|}{ Measles } \\
\hline $\begin{array}{l}\text { Seroimmune } \\
\mathrm{N}(\%)\end{array}$ & $96(97.95 \%)$ & $250(84.74 \%)$ & 123(88.48\%) & $88(85.43 \%)$ & $557(87.7 \%)$ \\
\hline \multirow{2}{*}{$\begin{array}{l}\text { MCA } \pm S D ~ I U / L \\
\text { Response rate to } \\
\text { revaccination } \\
\text { respond/total(\%) }\end{array}$} & $25.15 \pm 6.47$ & $17.63 \pm 7.21$ & $19.34 \pm 7.02$ & $17.17 \pm 7.42$ & $19.19 \pm 7.59$ \\
\hline & - & $26 / 28(92.8 \%)$ & $11 / 12(91.6 \%)$ & 9/10(90\%) & $46 / 50(92 \%)$ \\
\hline \multirow{2}{*}{\multicolumn{6}{|c|}{$\begin{array}{l}\text { Rubella: } \\
\text { Seroimmune } \\
\mathrm{N}(\%)\end{array}$}} \\
\hline & & & & & \\
\hline $\mathrm{MCA} \pm S D$ IU/L & $98(100 \%)$ & $221(74.91 \%)$ & $115(82.9 \%)$ & $84(81.55 \%)$ & $518(81.57 \%)$ \\
\hline \multirow{2}{*}{$\begin{array}{l}\text { Response rate to } \\
\text { revaccination } \\
\text { respond/ total(\%) }\end{array}$} & $25.01 \pm 2.29$ & $23.07 \pm 15.56$ & $24.67 \pm 12.51$ & $20.09 \pm 9.83$ & $23.36 \pm 13.14$ \\
\hline & - & $34 / 36(94.4 \%)$ & 15/16(93.7\%) & $7 / 7(100 \%)$ & $56 / 59(94.3 \%)$ \\
\hline
\end{tabular}

mMV: monovalent measles vaccine, MMR: measles-mumps-rubella vaccine, yr: year, Mo: month, MCA: mean concentrations of antibody, MR: measles rubella vaccine.

a: these 2 groups (C\&D) that were vaccinated with 2-dose of MMR vaccine after the age of 12 months: $16+15=31(12.8 \%)$ and $24+19=43(17.7 \%)$ were susceptible to measles and rubella respectively.

\section{Discussion}


Study showed that nearly more than $12 \%$ and $18 \%$ of the studied individuals serologically were susceptible to measles and rubella respectively. The highest rates of susceptibility to measles and rubella with $15.2 \%$ and $25 \%$ was observed among subjects in the age group B (15- 19 years old) who were born within 5 years just before national MR immunization and were vaccinated only initially with 2- dose of $\mathrm{mMV}$ at the age 9 and 15 months. Rubella immunity observed in this group was acquired by natural infection. However, they received additional dose of MMR vaccine just before school entrance (6 years ), 1-5 years laater. Also, study showed that $12.8 \%$ and $17.7 \%$ of subjects that were vaccinated with 2 - dose of MMR vaccine administered after the age of 12 months (group $C$ and $D$ ), were susceptible to measles and rubella, respectively. In this study the lowest rate of serosuseptibility to measles and rubella was detected among 20-33 years old adults that were MR revaccinated. Based on our findings, the main possible reasons for susceptibility to measles and rubella among our vaccinated population was SVF because of isolated IgG immunologic response to MMR revaccination in boosted susceptible individuals. Moreover, study revealed that revaccination of the levels of MCA acquired after revaccination of seroimmune subjects to measles and rubella with MMR vaccine did not resulted to enhanced specific immunity against both agents.

Our data showed that $98 \%$ and $100 \%$ of subjects of group A that were participated in the national program of MR immunization (age group 20-33 years) were serologically immune to measles and rubella, respectively. This long- term high- rate of protection could be attributed to MR vaccine or natural boosting years earlier. Because, the reported prevalence rates of measles immunity The measles seroprevalence rate among Iranian population studied years before MR campaign were much lower than observed in this study and are presented in Table $3^{(38-42)} .40 .7 \%{ }^{38} ; 54.7 \%{ }^{39} ; 55.4 \%{ }^{40} ; 72 \%^{41}$ and $91.6 \%{ }^{42}$. However, years after revaccination seroprevalence, studies among different age groups population revealed much higher levels of seroprotection: one year after MR campaign among 6- 29 years old subjects the rate were $87.5 \%$ ( $80.6 \%$ in younger age group) for measles and $91-99 \%$ for rubella ${ }^{(24)}$. The results of rubella seroprevalence studies indicated the majority of MR vaccinated subjects $84.7 \%$ to $99.6 \%$ acquired seroprotection (Table 3).After 7 years among pregnant women; $81.7 \%$ and $96 \%(26)$, and after 10 years $79.2 \%(27)$ and $96.2 \%$ respectively (Table 3 ). In a recent nationwide study among premarriage girl older than 15 years, (13-14 years after national MR camping), the seroprotection rates to measles and rubella was investigated. Nearly 1573 sera from 10 different provinces were included. Overall seroimmunity rate against measles,was $80.7 \%$ (range $73.1 \%$ - to $89.8 \%$ ) and against rubella $90.6 \%$ (range; $81.2-95 \%$ ) ${ }^{(43)}$. However, these rates were varied greatly between provinces. The relative high rate of seroprotection observed in our study and in these mentioned studies carried out years after national campaign could be attributed to positive impact of MR revaccination and/or possibly natural boosting among immunized population.

In this study, the highest rate of measles and rubella susceptibility was observed among group B (age range 15- 19 years) that were vaccinated not only with 2- doses of MV at the ages of 9 and 15 months without any history of rubella immunization also, they received one additional dose of MMR vaccine at school entrance (they received 3 doses of measles and one dose of rubella containing vaccine ). These 
rates of seronegative to MR detected in this age group nearly 10-13 years after last dose of MR vaccine are unusual and cumbersome and should raise concern. Because, there is not information about immune response to the initial measles immunization in this age group, the true reasons for this rate of susceptibility and vaccine failure is unclear. However, most probably it may be the result of SVF, because most of boosted susceptible subjects in this group only showed an IgG response to measles revaccination. The quality and durability of measles vaccine- induced immunity are dependent on a number of factors that relate both to the host and the vaccine. The most important and well-studied hostrelated determinant is the age that the first dose of vaccine administered ${ }^{(3,4,44)}$. The results of studies on the immunogenicity and vaccine efficacy of MV administered before the age of 12 and 15 months was lower than those older ages ${ }^{(3-5,42-44)}$. In this regard, in a prospective randomized trial by Redd etal ${ }^{(4)}$, the immunogenicity of measles component of MMR vaccine given at the ages 9,12 and 15-18 months ${ }^{(4)}$ was investigated. They found $98 \%$ seroconversion rate among 15 months vaccinees compared with $95 \%$ among those vaccinated at age of 12 and $81 \%$ at the age 9 months ${ }^{(3)}$. Also, a study by perez etal ${ }^{(4)}$ revealed that measles vaccination at the age $<12$ months was associated with a greater risk of primary vaccine failure (PVF). The negative effects was persisted after the second dose ${ }^{(4)}$. Similar to These data and conclusion were confirmed by a recent systematic review and meta-analysis ${ }^{(5,44)}$.

Otherwise, there are evidences that antibody concentrations decline and fall to low or undetectable levels over time ${ }^{(45-49)}$. In a study among differentage groups of children vaccinated against measles at the age of 9 and 15 months, seroimmunity rate 5 and 3 months after injection of first and second dose were $52.9 \%$ and $89.2 \%$, respectively. The rate decreased to $68 \%$ at the age 6 year and $40.5 \%$ at 10 years old. However, 9 months after boosting with one dose of measles vaccine at the age of 14 years, the rate increased to $96.8 \%$. Further more, in a longitudinal study on the kinetic of measles and rubella antibodies , by Kremer et al, results showed that both antibodies wane with time but, measles relatively fast ${ }^{(45)}$. Considering these evidences, the relative high rates of measles and rubella susceptibility observed among our study group B and other reported evidences, these seronegatively could be attributed to waning of acquired seroprotection over time (SVF) or possibly may be the result of PVF vaccine failure. Reduced vaccine effectiveness has been explained as due to primary or secondary vaccine failure. Vaccine failure may occur either because the immune response newer developed (PVF), or it waned overtime (SVF). To differentiate whether, the seronegatively developed either by PFV or SVF, two methods of assessment did exist. IgG avidity test and IgM immune response to revaccination . for this study we used IgM method, and no body showed positive response . this negative results most probably may be due to SVF. However, it may be to some late blood sampling or the result of a less sensitive assay. However, due to IgG seroconversion detected among boosted seronegative subjects most probably are the results of SVF. Study finding also indicated that rubella infection was endemic in the country because $75 \%$ of studied subjects without history of rubella vaccination got immunity to rubella by natural rubella virus infection during their life time.

Most study results from developed countries have shown that approximately $90-95 \%$ of children vaccinated at the age ${ }^{3} 12$ months produce sufficient specific antibodies against measles and rubella. The 
protection rates will increase up to $95-98 \%$ after the second dose vaccination and will persist for decades $^{(1,3-6)}$, although, achieved seroprotection rate may decline over time years after initial immunization ${ }^{(46-49)}$. In this study, nearly $12.8 \%$ and $17.7 \%$ of $7-15$ years old subjects attributed to group $C$ and $D$ (who were vaccinated with 2- dose of MMR vaccine administered after the age of 12 months) were serologically susceptible to measles and rubella, respectively. The exact reason for this lower rates than expected is not known. However, after revaccination nearly all boosted serosusceptible subjects by specific lgG antibodies seroconverted responded and changed to seropositive. This is an evidence of SVF. However, in this study waning of measles and rubella antibodies titer and seroprotection rates after the initial course of vaccination occur more faster relatively shorter time than expected ${ }^{(1,5,6,42)}$. The loss of acquired immunity within shorter duration of post- vaccination than that one would expected, based on published immunogenicity and vaccine efficacy reports is of concern ${ }^{(50,51)}$. Therefore, vaccine- related factors such as less potent vaccine because of more thermolabile strain, inadequate control of cold chain during shipment/ storage/ use/ and possibly other factors may be responsible ${ }^{(50-52)}$. The our assumption of less potency of vaccine is based on the results of studies that were designed to investigate the immunogenicity of MMR vaccine currently in use in the Iran. Majority of these studies showed lower than expected sero-conversion rates following the first and/ or the second dose of MMR vaccine after the age of 12 months (Table 5).

Table 4. Measles and Rubella seroprevalence rates demonstrated among different studies before and after MR campaign in Iran. 


\begin{tabular}{|c|c|c|c|c|c|c|}
\hline \multirow{2}{*}{ Author/province } & \multirow{2}{*}{$\begin{array}{l}\text { Relation to MR } \\
\text { campaign } 2003\end{array}$} & \multirow{2}{*}{$\begin{array}{l}\text { Years } \\
\text { of } \\
\text { study }\end{array}$} & \multirow{2}{*}{$\begin{array}{l}\text { No of Subjects } \\
\text { Age-groups }\end{array}$} & \multirow{2}{*}{$\begin{array}{l}\text { Tested } \\
\text { method }\end{array}$} & \multicolumn{2}{|c|}{ Prevalence Rate } \\
\hline & & & & & $M$ & $\mathrm{R}$ \\
\hline $\begin{array}{l}\text { Emami-Naeini } \\
\text { Shiraz }^{38}\end{array}$ & 3-yr before & 2000 & $\begin{array}{l}241 \text { medical } \\
\text { students }(19-25 \\
\text { yr) }\end{array}$ & ELISA & $40.7 \%$ & \\
\hline Yekta Uremia 39 & Months before & $2002-3$ & 835 (5-25 yr) & ELISA & $54.7 \%$ & - \\
\hline Saffar Sari 40 & Year before & 2002 & $590(15-25 y r)$ & ELISA & $55.4 \%$ & - \\
\hline $\begin{array}{l}\text { Zam,ani Tehran } \\
41\end{array}$ & $2 \mathrm{yr}$ before & 2001 & 1665 (6-11yr) & ELISA & $72 \%$ & - \\
\hline Salimi Tabriz ${ }^{42}$ & Yr before & 2002 & $225(5-25 \mathrm{yr})$ & HI test & $91.6 \%$ & - \\
\hline \multirow[t]{4}{*}{$\begin{array}{l}\text { Pourabbas } \\
\text { Shiraz }^{24}\end{array}$} & \multirow[t]{4}{*}{9 mo after } & \multirow[t]{4}{*}{$2004-5$} & \multirow[t]{4}{*}{$909(6-26 y r)$} & \multirow[t]{4}{*}{ ELISA } & $\begin{array}{l}6-10 \mathrm{yr} \\
80.6 \%\end{array}$ & $91.0 \%$ \\
\hline & & & & & $\begin{array}{l}11-15 \mathrm{yr} \\
72.7 \%\end{array}$ & $99.6 \%$ \\
\hline & & & & & $\begin{array}{l}16-20 \mathrm{yr} \\
84.9 \%\end{array}$ & $97 \%$ \\
\hline & & & & & $\begin{array}{l}21-25 \mathrm{re} \\
87.5 \%\end{array}$ & \\
\hline Yekta Uremia 25 & $1 \mathrm{yr}$ after & 2004 & 624 (6-25yr) & ELISA & $72.3 \%$ & - \\
\hline $\begin{array}{l}\text { Honarvar } \\
\text { Shiraz }^{26}\end{array}$ & 7 yr aafter & $\begin{array}{l}2010- \\
11\end{array}$ & 175 (16-24yr) & ELISA & $81.7 \%$ & $96 \%$ \\
\hline $\begin{array}{l}\text { Keshavarz } \\
\text { Tehran } 27\end{array}$ & $10 \mathrm{yr}$ after & 2014 & 53 (19-26 yr) & ELISA & $79.2 \%$ & $96.2 \%$ \\
\hline $\begin{array}{l}\text { Izadi Southeast } \\
28\end{array}$ & $12-13$ yr after & 2015 & $1056(16-20 \mathrm{yr})$ & ELISA & $91.7 \%$ & $87.4 \%$ \\
\hline $\begin{array}{l}\text { Kaarami } \\
\text { Hamadan } 29\end{array}$ & $13 \mathrm{yr}$ after & 2016 & $272(1-40 \mathrm{yr})$ & ELISA & $63.2 \%$ & - \\
\hline
\end{tabular}

Yr: year, mo: months

Table 5. Immunogenicity and seroconversion rate to measles and rubella component of MMR vaccine currently in use in Iran. 


\begin{tabular}{|c|c|c|c|c|c|c|c|}
\hline \multirow[t]{3}{*}{ Author/province } & \multirow{3}{*}{$\begin{array}{l}\text { Years } \\
\text { of } \\
\text { study }\end{array}$} & \multirow{3}{*}{$\begin{array}{l}\text { No of } \\
\text { Subjects }\end{array}$} & \multirow[t]{3}{*}{ Age } & \multicolumn{4}{|c|}{ Responses Rate MMR } \\
\hline & & & & \multicolumn{2}{|c|}{$\mathrm{MMR}^{1}(\%)$} & \multicolumn{2}{|c|}{$\operatorname{MMR}^{2}(\%)$} \\
\hline & & & & M & $\mathrm{R}$ & $M$ & $\mathrm{R}$ \\
\hline $\begin{array}{l}\text { Saffar, Mazandaran Razi- } \\
\operatorname{Iran}^{31}\end{array}$ & 2007 & 112 & $12.10 \mathrm{mo}$ & $\begin{array}{l}84.8 \% \\
\text { ELISA }\end{array}$ & $53 \%$ & - & - \\
\hline \multirow{4}{*}{$\begin{array}{l}\text { Saffar, Mazandaran } \\
\text { Razi-Iran }{ }^{33 \star}\end{array}$} & \multirow[t]{4}{*}{2011} & \multirow[t]{2}{*}{249} & \multirow{2}{*}{$\begin{array}{l}18 \mathrm{~m}(6 \mathrm{mo} \\
\text { after } \\
\text { MMR1) }\end{array}$} & $\begin{array}{l}74 \% \\
\text { ELISA }\end{array}$ & \multirow[t]{2}{*}{$75 \%$} & \multirow{2}{*}{\multicolumn{2}{|c|}{$\begin{array}{l}94.4 \% \quad 92.6 \% \\
\text { One mo after } \\
\text { MMR2 }\end{array}$}} \\
\hline & & & & \multirow[t]{3}{*}{$78.9 \%$} & & & \\
\hline & & \multirow{2}{*}{228} & \multirow{2}{*}{$\begin{array}{l}6 \mathrm{yr}(5 \mathrm{yr} \\
\text { after } \\
\text { MMR1) }\end{array}$} & & \multirow{2}{*}{$66 \%$} & 98.2 & $87 \%$ \\
\hline & & & & & & $\begin{array}{l}\text { One m } \\
\text { MMR2 }\end{array}$ & after \\
\hline \multirow{4}{*}{$\begin{array}{l}\text { Shamsizadeh, Ahwaz } \\
\text { Karaj-Iran Razi Iran }{ }^{34}\end{array}$} & \multirow{4}{*}{$\begin{array}{l}2010- \\
2011\end{array}$} & 70 & \multirow{2}{*}{$\begin{array}{l}18 \mathrm{mo}(6 \\
\text { mo after } \\
\left.\mathrm{MMR}_{1}\right)\end{array}$} & \multirow{3}{*}{$\begin{array}{l}42.9 \% \\
\text { ELISA } \\
-\end{array}$} & \multirow[t]{2}{*}{$90 \%$} & \multirow[t]{2}{*}{-} & \multirow[t]{3}{*}{-} \\
\hline & & 90 & & & & & \\
\hline & & & $6.5 \mathrm{yr} A^{*}$ & & & $45.6 \%$ & \\
\hline & & & & & - & & $87.8 \%$ \\
\hline Tabatabaei, Razi-Iran ${ }^{35}$ & $\begin{array}{l}2011- \\
2012\end{array}$ & 240 & $\begin{array}{l}13.27 \mathrm{mo} \\
(12-15)\end{array}$ & $\begin{array}{l}75.8 \% \\
\text { ELISA }\end{array}$ & $\begin{array}{l}73.8 \% \\
\text { ELISA }\end{array}$ & - & - \\
\hline \multirow{2}{*}{$\begin{array}{l}\text { Izadi, Bluchestan - } \\
\text { Kerman-Hormozgan Razi- } \\
\text { Iran }^{37}\end{array}$} & \multirow[t]{2}{*}{2015} & \multirow[t]{2}{*}{663} & \multirow[t]{2}{*}{$30-54 \mathrm{mo}$} & \multirow[t]{2}{*}{ - } & \multirow[t]{2}{*}{-} & $94.6 \%$ & - \\
\hline & & & & & & $\begin{array}{l}\text { After } \\
\text { revacc } \\
\text { dose o }\end{array}$ & $\begin{array}{l}\text { ation } \\
\text { MMR }\end{array}$ \\
\hline $\begin{array}{l}\text { Zahrari, Bluchestan - } \\
\text { Kerman-Hormozgan Razi- } \\
\text { Iran }{ }^{36}\end{array}$ & 2016 & 236 & $>12 \mathrm{mo}$ & $\begin{array}{l}91.2 \% \\
\text { ELISA }\end{array}$ & $B^{*}$ & - & \\
\hline
\end{tabular}

*: in these study seroconversion rates to rubella component of MMR vaccine after first dose of MMR was $75 \%$ among younger VS $67 \%$ older age groups, and with $\mathrm{MMR}_{2}$ increased to $87 \%$ and $92.4 \%$, respectively.

$A^{*}$ : one dose of MMR vaccine in addition to 2 dose $M V$ at age 9 and 15 month.

$B \star$ : Based on strict control of vaccination administration by researchers.

Waning of measles- rubella antibodies concentration post- vaccination may result to accumulation of potentially susceptible individuals to measles and/ or rubella in the community. In this regard, several 
reports describe a significant proportion of SVF in population with sustained high vaccination coverage and long absence of measles virus transmission ${ }^{(45-49)}$. In a prospective multicenter study by Smetana et al $^{(47)}$, measles IgG antibody concentrations among vaccinated subjects ${ }^{3} 18$ years was evaluated. Of 1911 sera, $83.3 \%$ were seropositive. When individual age groups were compared, antibody titers seroprevalence rate decreased overtime; $18-29$ year- $81.1 \%$; and $30-39$ years; $61.5 \%$. The results of similar study in Korea also indicated a progressive decline of antibody level and seroprotection rates as well as the avidity of antibodies over time among 2- 30 years old vaccinated persons ${ }^{(49)}$. Measles outbreaks investigation indicated that the vaccine failure was observed among $11-49 \%^{(11,52-55)}$ of measles cases in several large outbreaks, and in an epidemic up to $14 \%(53)$ of cases had received at least 2 - doses of measles vaccine $\mathrm{e}^{(11,43,44,52,53)}$. These data are in favor of SVF as the main cause of susceptibility among our studied subjects in the group C and D. However, because of faster development of SVF in these groups, further studies to evaluated the immunogenicity and long-term protection of measles vaccine in Iran are recommended.

The WHO Eastern Mediterranean Regional verification commission for measles and rubella elimination declared elimination of measles and rubella in Iran ${ }^{(30)}$. In our study among 7- 33 years- old individuals who were vaccinated at least with 2- doses of measles vaccine with different schedule, nearly $87 \%$ and $81 \%$ were sero-protected to measles and rubella respectively. Considering 2 - doses vaccine coverage $95 \%$, a population immunity of $83 \%$ and $77.6 \%$ could be estimated. This levels of immunity is below than that is required (93\%- $95 \%$ ) and $88-90 \%$ to interrupt measles and rubella viruses transmission in the community and maintain achieved measles and rubella elimination ${ }^{(1,6)}$. The point of concern is that the phylogenetic analysis of isolated measles virus in outbreaks in Iran showed major similarity with measles virus of neighbor countries that in some of these countries measles is endemic ${ }^{(16,31)}$. These raise concern and potentially is alarming. To confirm our data, further long-term prospective studies to evaluate the immunogenicity of MMR vaccine in use and the persistence of seroimmunity are recommended. If these data were confirmed by further studies, to sustain measles-rubella elimination in Iran additional dose of MMR vaccine as an national and/or regional supplementary immunization activity program among age group of $10-25$ years may be required ${ }^{(43)}$.

The potential limitation of our study is lack of information about post-primary vaccination seroimmunity status to can differentiate PVF than SVF exactly. Also, the assessment method of IgM response to revaccination probably was less sensitive. Another limitation include that study was done not designed as a population based study in East of Mazandaran province, north of Iran with a modest number of participants which made the results less generalizable. Also, and finally recall bias about MR vaccination in group A may exist.

\section{Conclusion}

Based on our data, nearly $12.3 \%$ and $18.4 \%$ of fully vaccinated $7-33$ years- old individuals were susceptible seronegative to measles and rubella respectively. The main causes of susceptibility negativity 
to measles and rubella was SVF. The levels of seroprotection detected in this study is lower than that is required to achieve/maintain elimination goal. To sustain measles and rubella elimination in Iran, further studies to assess the immunogenicity of MMR vaccine currently in use, along with strict monitoring of cold chain of vaccines in all process until usage, and periodic serosurveillance studies among different age groups of population in various provinces of the country to detect gaps in population immunity are recommended.

\section{Abbreviations}

mMV: monovalent measles Vaccine, MV: measles Vaccine, MMR: Measles Mumps Rubella, EPI: Expanded program of Immunization, CRS: Congenital Rubella Syndrome, PVF: Primary Vaccine Failure, SVF: Secondary Vaccine Failure, WHO: world health organization, MAZUMS: Mazandaran University of Medical Sciences, TUMS: Tehran University of Medical Sciences ELISA: enzyme immune assay, IU/L: international unit/ liter. IgG: Imunoglobulin G, IgM: Immunoglobulin M, MCA: mean Concentration Antibodies.

\section{Declarations}

Acknowledgment: The researchers would like to thank the participated sunjects and guardian for their participation in this study, and the health staff in the deputy of health for their help in recruiting personnel and blood sampling.

Authors Contributions: HS and MK, A-R A, S S: involved in study design, literature search, laboratory testing and writing the paper. M-R P, G-R G, MA: in Selection, recruiting, interviewing and blood sampling. MS participated in all study phases, (Conception, design, literature search, selection of eligible HCP, data collection and interpretation of the results writing the paper and finalizing the version to be published. All authors read and approved the final MS.

Funding: This study was funded by Vice-chancellor for research and Technology MAZUMS No: (IR.MAZUMS. Rec.1396.3074) and TUMS No: (IR.TUMS.IKHC. Rec.1399.075). The funders had no role in the design of study and collection, analysis, and interpretation and writing of manuscript.

Availability of data and materials: obtained for this study will be available from the corresponding author at a reason all request.

Ethic approval and Consent to Participate: The study was provided ethical approval by the Mazandaran No: IR.MAZUMS. Rec.1396.3074 and Tehran IR.TUMS.IKHC. Rec.1399.075. The study obtained the consent of all participants and signed and informed consent form prior to the investigation. They were assured about confidentially and that their contribution would be on a voluntary bases as well as that they had full rights to withdraw from the study at any time.

Consent for Publication: Not applicable 
Competing interests: The authors declare that they have no competing interest

Author's details: HS and MK, A-R A, S S: Department of antimicrobial and clinical Pathology, IKHC, Teheran University of Medical Sciences, Tehran Iran. M-R P, G-R G, MA: all Deputy of Health, Roudaki Ave MAZUMS, Sari, Iran. MS: Pediatrics Infectious Diseases Research Center, Bouali Hospital Pasdaran Bulv MAZUMS, Sari, Iran.

\section{References}

1. World Health Organization. Measles vaccine: WHO position paper. April 2017. WKLY Epidemiol Rec. No 17. 2017:92:205-228.

2. World Health Organization. Measle. Key factsheet: 5 Dec 2019. www.WHO.int/news-room/factsheet/detail measles.

3. Redd SC, King GE, Heath JL, Forghani B, Bellini WJ, et al. Comparison of vaccination with measlesmumps-rubella vaccine at 9, 12, and 15 months of age. J Infect Dis. 2004;189 Suppl 1:S116-22.

4. Perez SC, De Serres G, Bureau A, Skowronski DM Reduced Antibody Response to Infant Measles Vaccination: Effects Based on Type and Timing of the First Vaccine Dose Persist After the Second Dose. Clin Infeci Dis 2017;65(7):1094-1102

5. Uzicanin A, Zimmerman L.Field effectiveness of live attenuated measles-containing vaccines: a review of published literature. J Infect Dis. 2011;204 Suppl 1:S133-48.

6. Holzmann $\mathrm{H}$, Hengel $\mathrm{H}$, Tenbusch $\mathrm{M}$, Doerr HW. Eradication of measles: remaining challenges. Med Microbiol Immunol. 2016;205(3):201-8.

7. Center for Disease Control and Prevention (CDC). Global Measles Outbreaks. www.cdc.gov/global health/measles/global measles outbreaks. html.

8. Palamara MA, Visalli G, Picerno I, DI Pietro A, Puglisi G, et al. Measles outbreak from February to August 2017 in Messina, Italy. J Prev Med Hyg. 2018;59(1):E8-E13.

9. De Serres G, Markowski F, Toth E, Landry M, Auger D, Mercier M, et al.Largest measles epidemic in North America in a decade-Quebec, Canada, 2011: contribution of susceptibility, serendipity, and superspreading events. J Infect Dis. 2013;207(6):990-8.

10. Zipprich J, Winter K, Hacker J, Xia D, Watt J, Harriman K. Measles outbreak--California, December 2014-February 2015. MMWR Morb Mortal Wkly Rep. 2015;64(7):196.

11. Breakwell L, Moturi E, Helgenberger L, Gopalani SV, Hales C, et al. Measles Outbreak Associated with Vaccine Failure in Adults-Federated States of Micronesia, February-August 2014. MMWR Morb Mortal Wkly Rep. 2015 Oct 2;64(38):1088-92.

12. Nejati J, Sargolzaie N, Kiani M, Mahjoob M, Hashemi A. Measles epidemiology in sistan and baluchistan province during April 2006-March 2011. HEALTH SCOPE. 2013;2 (1): 58-62.

13. Izadi S, Zahraie SM, Sartipi M An investigation into a measles outbreak in southeast Iran. Jpn J Infect Dise, 2012;65(1):45-51. 
14. Moghadam M, Afsarkazerooni P, Ebrahimi M, Soltani M, Razmpoor A, et al. Measles outbreak in South of iran, where vaccine coverage was high: a case-series study. Iran J Public Health. 2014;43(3):375-80.

15. Karami M, Zahraei SM, Sabouri A, Soltanshahi R, Biderafsh A, et al. Documentation of Measles Elimination in Iran: Evidences from 2012 to 2014. J Res Health Sci. 2017;17(3):e00387.

16. Piri N, Karami M, Tapak L, Zahraei M, Mohammadi Y. Monitoring Progress towards the elimination of measles in Iran: supporting evidence from 2014 to 2016 by application of measles outbreaks data. BMC Public Health. 2019;19(1):687.

17. Lambert N, Strebel P, Orenstein W, Icenogle J, Poland GA.Lambert N, et al. Rubella. 2015;385(9984):2297-307.

18. World Health Organization. Rubella. Key facts: 4 Oct 2019. www.WHO.int/news-room/factsheets/detail/Rubella.

19. Zahraei SM, Gouya MM, Azad TM, Soltanshahi R, Sabouri A, et al. Successful control and impending elimination of measles in the Islamic Republic of Iran. J Infect Dis. 2011;204 Suppl 1:S305-11.

20. Saffar MJ, Ajami A, Pourfatemi F. An Immunological Study in the Pregnant women infected with Rubella virus in mazandaran province in 1999-2000. Nameh Daneshgah (J. Mazandaran Univ of Med Scien, 2001;11(3):1-6. (In Persian).

21. Hamkar R, Jalilvand S, Abdolbaghi MH, Jelyani KN, Esteghamati A, et ar.Distinguishing between primary infection and reinfection with rubella vaccine virus by $\lg \mathrm{G}$ avidity assay in pregnant women. East Mediterr Health J. 2009;15(1):94-103.

22. Azami M, Jaafari Z, Soleymani A, Badfar GH, Abbasalizadeh SH. Rubella Immunity in Pregnant Iranian Women: A Systematic Review and Meta-Analysis. Int J Fertil Steril. 2019;13(3):169-177.

23. Sadighi J, Eftekhar H, Mohammad K. Congenital rubella syndrome in Iran. BMC Infect Dis. 2005;5:44.

24. Pourabbas B, Ziyaeyan M, Alborzi A, Mardaneh J. Efficacy of measles and rubella vaccination one year after the nationwide campaign in Shiraz, Iran. Int J Infect Dis. 2008;12(1):43-6.

25. Yekta Z, Pourali R, Taravati MR, Shahabi S, Salary S, et al. Immune response to measles vaccine after mass vaccination in Urmia, Islamic Republic of Iran. East Mediterr Health J. 2009 MayJun;15(3):516-25.

26. Honarvar B, Moghadami M, Moattari A, Emami A, Odoomi N, et al. Seroprevalence of anti-rubella and anti-measles IgG antibodies in pregnant women in Shiraz, Southern Iran: outcomes of a nationwide measles-rubella mass vaccination campaign. PLoS One. 2013;8(1):e55043.

27. Keshavarz M, Nicknam MH, Tebyanian M, Shahkarami MK, Izad M. Anti-rubella, Mumps and Measles IgG Antibodies in Medical Students of Tehran University. Iran J Allergy Asthma Immunology 2016;15(3):244-250.

28. Izadi S, S Zahraei, T Mokhtari-Azad. Seroprevalence of antibodies to measles and rubella eight months after a vaccination campaign in the southeast of Iran. HumVacci \& Immunother 2018;14(6):1412-6. 
29. Karami M, Khazaei S, Zahraei SM, Mokhtari Azad T, Zahiri A, et al. Measles Outbreak in a Rural Population in Bahar District, Hamadan Province, West of Iran in 2018. J Res Healt Scien. 2020; 20(1): e00470.

30. Teleb N1, Atta H2, Hajjeh R3. Measles and rubella elimination in the Eastern Mediterranean Region: successes and challenges. East Mediterr Health J. 2019;25(10):667-668.

31. Salimi V, Abbasi S, Zahraei SM, Fatemi-Nasab G, Adjaminezhad-Fard F, et al. Implementation of a national measles elimination program in Iran: Phylogenetic analysis of measles virus strains isolated during 2010-2012 outbreaks. PLoS One. 2014;9(4):e94846.

32. Saffar MJ, Ajami A, Khalilian AR, Saffar H. The impact of maternal measles-rubella immunization on the 12-month-old infant's immune response to measles-mumps-rubella vaccine immunogenicity. Eur $\mathrm{J}$ Clin Microbiol Infect Dis. 2009;28(7):845-7.

33. Saffar MJ, Fathpour GR, Parsaei MR, Ajami A, Khalilian AR, et al. Measles-mumps-rubella revaccination; 18 months vs. 4-6 years of age: potential impacts of schedule changes. J Trop Pediatr. 2011;57(5):347-51.

34. Shamsizadeh A, Nikfar R, Makvandi M, Hakimzadeh M, Alisamir, et al. Seroprevalence of measles, mumps and rubella Antibodies in 18 months and 6.5 years old children: 6 months after measlesmumps-rubella (MMR) vaccination. Jundishapur J Microbiol. 2012;5(4):578-581.

35. Rafiei Tabatabaei S, Esteghamati AR, Shiva F, Fallah F, Radmanesh R, et al. Detection of serum antibodies against measles, mumps and rubella after primary measles, mumps and rubella (MMR) vaccination in children. Arch Iran Med. 2013;16(1):38-41.

36. Zahraei SM, Izadi S, Mokhtari-Azad T. Factors affecting the seroconversion rate of 12-month-old babies after the first injection of measles vaccine in the southeast of Iran. Hum Vaccin Immunother. 2016;12(12):3118-3124.

37. Izadi S, Mokhtari-Azad T, Zahraei SM. Measles vaccination coverage and seroprevalence of antimeasles antibody in south-east Islamic Republic of Iran. East Mediterr Health J. 2015;21(6):396-402.

38. Emami Naeini A.R, Davarpanah M.A, Sherkat R., Karimi I, Hashemi J. Should We Consider another Booster Dose of Measles Vaccine? IR J Med Scienc 2002;27(1):1-3.

39. Yekta Z, Porali R, Taravati MR, Salary Sh, Khalily F, et al. Measles IgG sero-prevalence and its attributable factors in 5-25-year-old cases prior mass vaccination campaign in Urmia, northeastern Iran. Iran Red Crescent Med J. 2007; 9(1):e95867.

40. Saffar MJ, Alraza-Amiri M, Ajami A, Baba-Mahmoodi F, Khalilian A.R, et al. Measles seroepidemiology among adolescents and young adults: response to revaccination. East Mediterr Health J 2006;12(5):573-581.

41. Zamani A, Daneshjou K. Seroepidemiology of Measles in Primary School Students in Tehran, Iran. Trends in Med Res 2006;1(1)39-48.

42. Salimi V, Mokhtari-Azad T, Gooya MM, Hamkar R, Esteghamati AR, et al. Seroepidemiology of Measles in 5-25 year old age group before Measles/Rubella Mass Vaccination campaign in Tabriz (2003). Med J Tabriz Unive Med Scien 2006;28(2): 77-82 (In Persian). 
43. Zahraei SM, Mokhtari-Azad T, Izadi S, Mohammadi M, Sabouri A. Seroprevalence of anti-rubella and anti-measles antibodies in women at the verge of marriage in Iran. Vaccine. 2020;38(2):235-241.

44. Carazo S, Billard MN, Boutin A, Serres GD. Effect of Age at Vaccination on the Measles Vaccine Effectiveness and Immunogenicity: Systematic Review and Meta-Analysis. BMC Infect Dis. 2020;20(1):251.

45. Karimi A, Arjomandi A, Alborzi A, Rasouli M, Kadivar MR, et al. Prevalence of measles antibody in children of different ages in Shiraz, Islamic Republic of Iran. East Mediterr Health J. 2004 JulSep;10(4-5):468-73.

46. Kremer JR, Schneider F, Muller CP. Waning antibodies in measles and rubella vaccinees--a longitudinal study. Vaccine. 2006 Mar 24;24(14):2594-601.

47. Kontio M, Jokinen S, Paunio M, Peltola H, Davidkin I. Waning antibody levels and avidity: implications for MMR vaccine-induced protection. J Infect Dis. 2012;206(10):1542-8.

48. Smetana J, Chlibek R, Hanovcova I, Sosovickova R, Smetanova L, et al. Decreasing Seroprevalence of Measles Antibodies after Vaccination - Possible Gap in Measles Protection in Adults in the Czech Republic. PLoS One. 2017;12(1):e0170257.

49. Kang HJ, Han YW, Kim SJ, Kim YJ, Kim AR, et al. An increasing, potentially measles-susceptible population over time after vaccination in Korea. Vaccine. 2017;35(33):4126-4132.

50. Velicko I, Müller LL, Pebody R, Gergonne B, Aidyralieva C, et al. Nationwide measles epidemic in Ukraine: the effect of low vaccine effectiveness. Vaccine. 2008;26(52):6980-5.

51. Atrasheuskaya AV, Kulak MV, Neverov AA, Rubin S, Ignatyev GM. Measles Cases in Highly Vaccinated Population of Novosibirsk, Russia, 2000-2005. Vaccine. 2008;26(17):2111-8.

52. Saffar H, Saffar MJ, Saffar H. Vaccination in Developing Countries: A Review of Probable Factors for Lower Responses to Vaccine. J Pediatr Rev. 2013;1(1) 12-18.

53. Defay F, De Serres G, Skowronski DM, Boulianne N, Ouakki M, et al. Measles in children vaccinated with 2 doses of MMR. Pediatrics. 2013;132(5):e1126-33.

54. Cherry JD, Zahn M. Clinical Characteristics of Measles in Previously Vaccinated and Unvaccinated Patients in California. Clin Infect Dis. 2018;67(9):1315-1319.

55. Bernadou A, Astrugue C, Méchain M, Le Galliard V, Verdun-Esquer C, et al. Measles outbreak linked to insufficient vaccination coverage in Nouvelle-Aquitaine Region, France, October 2017 to July 2018. Euro Surveill. 2018;23(30):1800373.

56. De Serres G, Boulianne N, Defay F, Brousseau N, Benoît M, et al. Higher risk of measles when the first dose of a 2-dose schedule of measles vaccine is given at 12-14 months versus 15 months of age. Clin Infect Dis. 2012;55(3):394-402. 